\title{
Detection of Circulating Tumor Cells in Colorectal Cancer by Immunobead- PCR Is a Sensitive Prognostic Marker for Relapse of Disease
}

\author{
Jennifer E. Hardingham,*† Dusan Kotasek,* Robert E. Sage,*\| \\ Michael C. Eaton, ${ }^{\neq}$Vivienne H. Pascoe, ${ }^{\S}$ \\ and Alexander Dobrovic*ll
}

Departments of *Hematology-Oncology, ${ }^{\star}$ Surgery, and

§Histopathology, The Queen Elizabeth Hospital, Woodville, South Australia

†Departments of Physiology and "Medicine, University of Adelaide, Adelaide, South Australia

\begin{abstract}
Background: Recurrent and metastatic carcinoma of the colorectum remains a major problem, with survival at 5 years post curative resection still only about $50 \%$. Moreover, up to $30 \%$ of patients who present with early stage disease also relapse and die within 5 years, suggesting the presence of micrometastatic disease at diagnosis. One route of metastatic spread is via the blood stream, hence the detection of tumor cells in blood is likely to provide an important predictive tool with respect to relapse of disease. We have developed a sensitive molecular technique to identify tumor cells in blood using mutations in codon 12 of the $\mathrm{K}$-ras gene as a marker.

Materials and Methods: Twenty-seven patients whose tumor carried a mutation in codon 12 of $\mathrm{K}$-ras were studied for the presence of tumor cells in perioperative peripheral blood samples. Immunomagnetic beads, labeled with an epithelial-specific antibody, were used to
\end{abstract}

harvest epithelial cells from blood. K-ras mutations were identified in this selected population using a polymerase chain reaction (PCR)-based analysis (immunobeadPCR).

Results: Circulating K-ras mutant cells were detected in 9 of 27 patients; seven of these nine patients have since died due to recurrent or metastatic disease. Mutant cells were not detected in 18 patients, and 16 of 18 have remained disease free (median follow-up: 16 months; range: 7-42 months). Kaplan-Meier analysis showed that detection of K-ras mutant cells in blood was associated with significantly reduced disease-free survival $(p=0.0001)$.

Conclusion: This study indicates that detection of circulating tumor cells perioperatively by immunobeadPCR provides a sensitive prognostic marker for recurrent and metastatic colorectal cancer.

\section{INTRODUCTION}

Despite recent advances in surgical and diagnostic techniques, a significant number of patients with early stage colorectal cancer who undergo

Address correspondence and reprint requests to: A. Dobrovic, Hematology-Oncology Department, The Queen Elizabeth Hospital, 28 Woodville Road, Woodville, South Australia 5011. "curative" resection, still suffer recurrent and metastatic disease and die within 5 years (1). The inference is that occult metastatic disease was already present at diagnosis, or that tumor cells with metastatic potential were released into the blood at the time of surgery. Detection of circulating tumor cells preoperatively in these "good prognosis" patients would imply that the disease is more advanced than indicated by conventional 
staging. These patients might then also be offered adjuvant chemotherapy or radiotherapy post surgery.

Mutations in codon 12 of the K-ras gene have been identified as an early event in the development of up to $50 \%$ of colorectal tumors (2). Identification of this mutation in a tumor thus provides a marker for tumor cells that may be present in the blood. We have developed a sensitive method, immunobead-polymerase chain reaction (PCR), for the detection of tumor cells bearing this mutation in blood ( 3 ) and have used this technique to address the question of the tumorigenic potential of $\mathrm{K}$-ras-positive cells in the peripheral circulation and tumor cell release during surgical resection.

The process of metastasis involves sequential steps of tumor cell detachment from the primary tumor, adherence to and proteolysis of endothelial basement membranes, intravasation into the circulation, and initiation of secondary tumors in distal organs. Most of the tumor cells that enter the circulation die, and only a very small proportion succeed in establishing metastases $(4,5)$. The aims of this study were to detect the presence of circulating tumor cells perioperatively and to determine the relationship of tumor cells in blood to disease-free survival following curative resection for colorectal cancer.

\section{MATERIALS AND METHODS}

\section{Patients and Samples}

Twenty-seven consecutive patients whose colorectal tumor was positive for a K-ras codon 12 mutation were included in the study. The disease was staged according to the Dukes' classification (Astler Coller modified) (1). The median age was 74 years (range: 56-91) with 13 males and 14 females. The study was approved by the institutional Ethics of Research Committee and informed consent was obtained from each patient. Tumor specimens were obtained either fresh, or from formalin fixed, paraffin-embedded sections. Peripheral venous blood samples $(20 \mathrm{ml})$ were collected before surgery from 24 cases, and post surgery from 26 cases (immediately after mobilization of the tumor in 13 cases and the following morning in 24 cases). Normal controls consisted of $20-\mathrm{ml}$ blood samples from 11 nonsurgical patients without cancer and from two patients undergoing colonic surgery for benign disease.

\section{Immunobead-PCR Analysis}

Tumor samples were analyzed for K-ras codon 12 mutations by PCR as previously described (3). Following digestion of PCR products with BstN1 (New England Biolabs, Beverly, MA, U.S.A.), the restriction enzyme fragments were run on a $10 \%$ polyacrylamide (19:1 acrylamide:bisacrylamide) gel and visualized by ethidium bromide or silver staining (6).

To detect tumor cells in blood, the immunobead-PCR technique was performed (3). Firstly, epithelial cells were isolated from blood using immunomagnetic beads (Dynal, Oslo, Norway) labeled with the epithelial-specific antibody BerEP4 (Dakopatts, Gestrop, Denmark). This antibody was found to react strongly with all 27 tumor samples, either by flow cytometry or immunohistochemistry. Secondly, the PCR analysis was performed as described above, on the isolated epithelial cell/bead aggregates to determine the presence of a K-ras mutation. The sensitivity of detection of $\mathrm{K}$-ras mutations using immunobead-PCR and silver staining was in the order of 1 tumor cell $/ 10^{6}$ white blood cells (i.e., 10 tumor cells/ml of whole blood [data not shown]). The study was performed in a blinded fashion such that the patients' clinical details and histopathology were unknown to the investigator performing immunobead-PCR on the blood samples. A univariate Kaplan-Meier analysis (BMDP Statistical Software Inc., Los Angeles, CA, U.S.A.) was used to assess the significance of circulating $\mathrm{K}$-ras mutant cells with respect to disease-free survival in our patient cohort.

\section{RESULTS}

$\mathrm{K}$-ras mutant cells were detected in perioperative peripheral blood samples in 9 of 27 (33\%) patients (Table 1). Results from blood taken post mobilization of the bowel and day 1 post surgery were combined since no additional information was obtained from those 11 cases (three positive, eight negative) in which we tested both samples. In six of nine patients, mutant cells were detected in blood samples before surgery indicating that tumor dissemination had already occurred. Five of the six patients (Table 1, Nos. 17, 18, 20, 21 , and 25) have relapsed and died from recurrent or metastatic disease at a median of 14 months (range: 7-23 months) post surgery. The other patient (No. 5) had been staged as Bl (tumor contained within the muscularis propria 
TABLE 1. Patient characteristics and detection of tumor cells in blood

\begin{tabular}{|c|c|c|c|c|c|c|c|c|c|}
\hline \multirow[b]{2}{*}{$\begin{array}{l}\text { Patient } \\
\text { No. }\end{array}$} & \multirow[b]{2}{*}{$\begin{array}{l}\text { Patient } \\
\text { ID }\end{array}$} & \multirow[b]{2}{*}{ Age } & \multirow[b]{2}{*}{ Sex } & \multicolumn{2}{|c|}{ Tumor Cells } & \multirow[b]{2}{*}{ Stage } & \multirow[b]{2}{*}{$\begin{array}{c}\text { Relapse } \\
\text { (months) }\end{array}$} & \multirow[b]{2}{*}{$\begin{array}{c}\text { Survival } \\
\text { (months) }\end{array}$} & \multirow[b]{2}{*}{ Status } \\
\hline & & & & $\begin{array}{c}\text { Pre- } \\
\text { Op }\end{array}$ & $\begin{array}{l}\text { Post- } \\
\text { Op }\end{array}$ & & & & \\
\hline 1 & 535 & 73 & M & Neg & Neg & A & Nil & 23.5 & Alive \\
\hline 2 & 425 & 56 & $\mathrm{~F}$ & Neg & Neg & A & Nil & 23 & Alive \\
\hline 3 & 169 & 64 & M & Neg & Pos & $\mathrm{A}$ & Nil & 17.5 & Alive \\
\hline 4 & 173 & 79 & M & Neg & Neg & $\mathrm{Bl}$ & Nil & 38 & Alive \\
\hline 5 & 304 & 68 & $\mathrm{~F}$ & Pos & Pos & $\mathrm{B} 1$ & Nil & 15 & Alive \\
\hline 6 & 954 & 82 & $\mathrm{~F}$ & Neg & Neg & $\mathrm{B} 1$ & Nil & 28 & Alive \\
\hline 7 & 711 & 77 & $M$ & Neg & Neg & $\mathrm{B} 1$ & Nil & 15 & Alive \\
\hline 8 & 647 & 65 & $M$ & Neg & Neg & $\mathrm{B} 1$ & Nil & 15 & Alive \\
\hline 9 & 177 & 88 & $\mathrm{~F}$ & Neg & Neg & $\mathrm{Bl}$ & Nil & 16 & $\operatorname{Dec}^{a}$ \\
\hline 10 & 966 & 80 & $M$ & NA & Neg & B2 & Nil & 42 & Alive \\
\hline 11 & 988 & 69 & $M$ & Neg & Neg & B2 & Nil & 14 & Alive \\
\hline 12 & 703 & 72 & $M$ & Neg & Neg & $\mathrm{B} 2$ & Nil & 16 & Alive \\
\hline 13 & 356 & 60 & $\mathrm{~F}$ & NA & Pos & B2 & $7 \mathrm{~m}$ & 10 & Dec \\
\hline 14 & 712 & 91 & $\mathrm{~F}$ & Neg & Neg & B2 & Nil & 37.5 & Alive \\
\hline 15 & 831 & 76 & $M$ & Neg & Neg & B2 & Nil & 29 & Alive \\
\hline 16 & 433 & 76 & $\mathrm{~F}$ & Neg & Neg & B2 & Nil & 30 & Alive \\
\hline 17 & 840 & 80 & $\mathrm{~F}$ & Pos & Pos & B2 & $4 \mathrm{~m}$ & 7 & Dec \\
\hline 18 & 352 & 82 & $\mathbf{M}$ & Pos & NA & B2 & $22 \mathrm{r}$ & 23 & Dec \\
\hline 19 & 925 & 79 & $F$ & Neg & $\mathrm{Neg}$ & $\mathrm{Cl}$ & Nil & 12.5 & Alive \\
\hline 20 & 606 & 59 & $M$ & Pos & Pos & $\mathrm{Cl}$ & $14.5 \mathrm{r}, \mathrm{m}$ & 18 & Dec \\
\hline 21 & 477 & 68 & $\mathrm{~F}$ & Pos & Pos & $\mathrm{Cl}$ & $4 \mathrm{~m}$ & 10 & Dec \\
\hline 22 & 748 & 75 & $\mathrm{~F}$ & Neg & Pos & $\mathrm{Cl}$ & $5 \mathrm{r}$ & 9.5 & Dec \\
\hline 23 & 43 & 73 & $M$ & Neg & Neg & $\mathrm{Cl}$ & Nil & 32 & $\operatorname{Dec}^{a}$ \\
\hline 24 & 895 & 71 & $\mathrm{~F}$ & Neg & Neg & $\mathrm{C} 2$ & Nil & 33 & Alive \\
\hline 25 & 412 & 63 & $\mathrm{~F}$ & Pos & Pos & $\mathrm{D}$ & $1 \mathrm{~m}$ & 7 & Dec \\
\hline 26 & 195 & 83 & $\mathrm{~F}$ & Neg & Neg & $\mathrm{D}$ & $6 \mathrm{r}, \mathrm{m}$ & 8 & Dec \\
\hline 27 & 625 & 76 & $M$ & NA & Neg & D & $7 \mathrm{r}$ & 7 & Dec \\
\hline
\end{tabular}

r, local recurrence; m, metastasis; NA, not available; Dec, deceased.

${ }^{a}$ Died of unrelated causes.

and no nodal metastases) and is presently disease free at 15 months. Tumor cells were also present in postoperative blood in all but one of these six patients (in this patient we did not receive a postsurgery specimen). K-ras positive cells were not detected in any of the normal control samples.

There were two cases in which tumor cells were detected in the postoperative but not the preoperative blood specimen, suggesting that tumor cells were shed into the circulation during surgical resection. One of these patients (No. 3 ) is alive at 17.5 months post surgery; the other (No. 22) suffered a local recurrence and died 9.5 months post surgery. In the remaining case (No. 13), tumor cells were found in postoperative blood, but we did not receive a presurgery blood sample; this patient, who was staged as B2, developed a metastatic deposit in the bladder and died 10 months post surgery.

Overall, 9 of 27 patients subsequently relapsed with either local recurrence or metastatic disease or both, and seven of the nine had circulating tumor cells detected in perioperative blood 


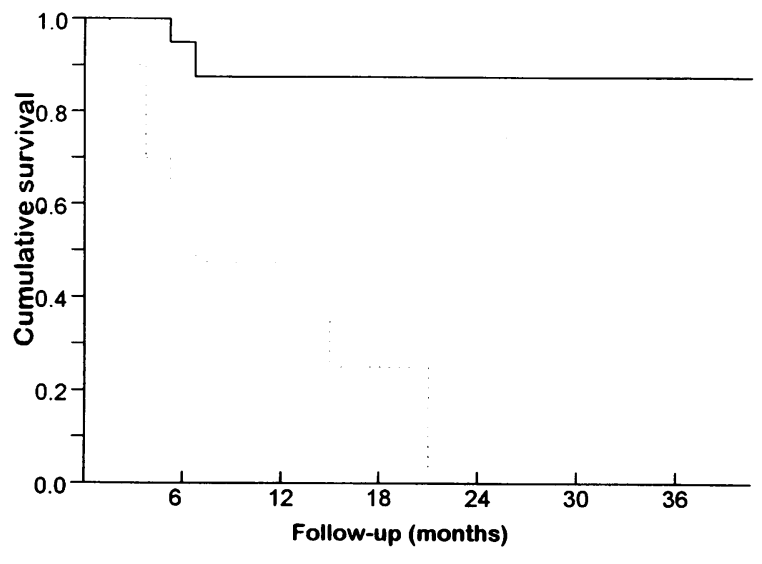

FIG. 1. Kaplan-Meier disease-free survival analysis

Solid line, patients in whom tumor cells were not detected; dashed line, patients in whom tumor cells were detected, $p=0.0001$.

specimens. Of 18 patients who have remained disease free post surgery, 16 of 18 were negative for circulating tumor cells at the time of surgery (median follow-up: 24 months; range: 12.5-42 months). Kaplan-Meier analysis (Fig. 1) showed that disease-free survival was significantly reduced $(p=0.0001)$ in patients in whom circulating tumor cells were detected (mean survival time: 11.2 versus 30.4 months; SE 2.88 months).

\section{DISCUSSION}

Tumor cells were detected in perioperative peripheral blood samples in a third of the patients, and this finding showed a strong association with shortened disease-free survival (Fig. 1). Due to the small number of patients in this study, we were not able to show whether or not detection of tumor cells in blood was independent of stage as a prognostic indicator.

Intravasation of viable tumorigenic cells into the blood stream is one step in the metastatic cascade leading to dissemination of the primary tumor. The presence of tumor cells in the circulation before surgery suggests that an active metastatic process is involved, and five out of six patients succumbed to recurrent or metastatic disease within 2 years of surgery. The presence of tumor cells in the circulation in two patients appeared to be due to direct release of tumor cells during surgical resection, as they were negative for tumor cells in blood before surgery but positive post surgery. One of these patients (Table 1, No. 22) suffered a local recurrence which may have arisen from a preexisting subclinical adenoma, or may have occurred as a result of "reseeding" of the mucosa by blood-borne tumorigenic cells. The other patient (Table 1, no. 3) has remained disease-free at 17.5 months post surgery, so perhaps tumor cells that gain direct access into the circulation may not necessarily have metastatic potential; Tarin et al. (7) demonstrated the absence of metastatic disease in some patients after months of continuous infusion of malignant ascites fluid into the bloodstream.

Previously, conventional cytology and immunocytochemistry have been used to detect tumor cells in blood. An immunofluorescence method, using the anti-cytokeratin antibody AE3, detected carcinoma cells in blood from the renal vein in 8 of 10 patients undergoing nephrectomy for renal carcinoma; three of eight patients had clinically detectable metastases prior to the assay, while five of eight have remained disease free for up to 35 months (8), suggesting that most of the tumor cells released into the renal vein were arrested and destroyed in the pulmonary microvasculature. Another study, using both cytology and immunocytochemistry, detected circulating colorectal cancer cells in 4 of 42 patients, including 2 of 4 with Dukes' B disease (9). The low detection rate was attributed to the fact that strict morphological criteria was applied in determination of malignant cells. Immunocytochemistry for an epithelial marker, cytokeratin 18, was used by Lindemann et al. (10) to determine the prognostic significance of tumor cells in bone marrow taken preoperatively from patients with colorectal cancer, $32 \%$ of the patients were positive and these patients had a significantly reduced disease-free survival.

More recently, the molecular techniques of reverse transcription and PCR have been used to detect very small numbers of tumor cells in blood in a range of neoplasms (11-15); however, results from these studies were not correlated with clinical outcome after long-term follow-up. Brown et al. (15) detected breast carcinoma cells in preoperative blood in of nine patients, in intraoperative blood in four of nine, but in zero of nine in blood collected $24 \mathrm{hr}$ post surgery, suggesting a proportion of tumors shed cells as a result of surgery and that they were removed from the circulation within $24 \mathrm{hr}$. This is in contrast to our findings, where eight patients were 
positive for tumor cells in peripheral blood taken 16-24 hr post surgery.

The biological significance of very small numbers of tumor cells in the circulation remains to be elucidated. A study by Mayhem and Glaves (16) using a murine model of metastasis for Lewis lung carcinoma determined that 1000 Lewis carcinoma cells were needed to generate at least one pulmonary metastasis. At the limit of detection of tumor cells using our assay (i.e., 10 tumor cells $/ \mathrm{ml}$ of blood), some 50,000 tumor cells may be circulating (based on an average blood volume of $5 \mathrm{l}$ ) at a given time point. If similar tumor kinetics can be applied to human carcinoma, then this implies that 50,000 circulating tumor cells would provide sufficient tumorigenic cells to enable metastases to form. Taking into account the inefficiency of the metastatic process such that less than $0.01 \%$ of these cells will survive $(17,18)$, there is still the potential for some five metastatic deposits to develop. The observed frequency is even less in our patient group, with only two patients developing secondary deposits at more than one site, although multiple seeding at the same site cannot be excluded.

In two patients with stage $\mathrm{D}$ (metastatic) disease we did not find circulating tumor cells prior to surgery and this may reflect the sporadic release of tumor cells from the primary (or secondary) tumor(s) into the blood (19). Hence, samples taken at any one time will necessarily contain variable numbers of cancer cells perhaps below the threshold of detection, depending on the rate of shedding at the time.

Our study has identified circulating tumor cells at the time of surgery in five patients whose tumors did not show any evidence of metastasis by conventional staging. These patients would not have been offered adjuvant therapy since this is currently restricted to patients with more advanced disease. Perhaps patients with circulating micrometastatic disease would benefit most from adjuvant chemotherapy or radiotherapy, or systemic treatment with monoclonal antibodies such as 17-1 A, which in Dukes' $\mathrm{C}$ patients has been shown to reduce the overall death rate by $30 \%$ and the recurrence rate by $27 \%(20)$.

In conclusion, this preliminary study shows that $\mathrm{K}$-ras immunobead-PCR is a sensitive and specific technique for identifying tumor cells in blood. The correlation between the presence of tumor cells in blood and shortened disease-free survival shows that the technique is useful for identifying colorectal patients at diagnosis who are at increased risk of relapse. This should result in a more appropriate selection of patients for further treatment and so lead to a reduction in morbidity and mortality in these patients.

\section{ACKNOWLEDGMENTS}

This work was supported by a grant from the Anticancer Foundation of the Universities of South Australia. The cooperation of the Department of Surgery, in particular Assoc. Professor W. E. W. Roediger, was greatly appreciated. We thank Mrs. Jing-Xian Mi for excellent technical assistance.

\section{REFERENCES}

1. Cohen AM, Shank B, Friedman MA. (1989) Colorectal cancer. In: Devita VT, Hellman S, Rosenberg SA (eds). Cancer: Principles and Practice of Oncology. 3rd ed. Lippincott, Philadelphia, pp. 895-952.

2. Bos JL. (1989) ras oncogenes in human cancer: A review. Cancer Res. 49: 4682-4689.

3. Hardingham JE, Kotasek D, Farmer B, et al. (1993) Immunobead-PCR: A technique for the detection of circulating tumor cells using immunomagnetic beads and the polymerase chain reaction. Cancer Res. 53: 3455-3458.

4. Fidler IJ. (1991) Cancer metastasis. Br. Med. Bull. 47: 157-177.

5. Liotta LA, Stetler-Stevenson WG. (1991) Tumor invasion and metastasis: An imbalance of positive and negative regulation. Cancer Res. 51(Suppl): 5054s-5059s.

6. Bassam BJ, Caetano-Anolles G. (1993) Silver staining of DNA in polyacrylamide gels. Appl. Biochem. Biotechnol. 42: 181-188.

7. Tarin D, Price JE, Kettlewell MGW, Souter RG, Vass ACR, Grossley B. (1984) Mechanisms of human tumor metastases studied in patients with peritoneovenous shunts. Cancer Res. 44: 3584-3592.

8. Glaves D, Huben RP, Weiss L. (1988) Haematogenous dissemination of cells from human renal adenocarcinomas. Br. J. Cancer 57: 32-35.

9. Leather AJM, Gallegos NC, Kocjan G, et al. (1993) Detection and enumeration of circulating tumour cells in colorectal cancer. $\mathrm{Br}$. $J$. Surg. 80: 777-780.

10. Lindemann $F$, Schlimok $G$, Dirschedl $P$, Witte J, Riethmuller G. (1992) Prognostic 
significance of micrometastatic tumour cells in bone marrow of colorectal cancer patients. Lancet 340: 685-689.

11. Smith B, Selby P, Southgate J, Pittman K, Bradley C, Blair GE. (1991) Detection of melanoma cells in peripheral blood by means of reverse transcriptase and polymerase chain reaction. Lancet 338: 1227-1229.

12. Mattano LA, Moss TJ, Emerson SG. (1992) Sensitive detection of rare circulating neuroblastoma cells by the reverse transcriptasepolymerase chain reaction. Cancer Res. 52: 4701-4705.

13. Seiden MV, Kantoff PW, Krithivas K, et al. (1994) Detection of circulating tumor cells in men with localized prostate cancer. J. Clin. Oncol. 12: 2634-2639.

14. Datta YH, Adams PT, Drobyski WR, Ethier SP, Terry VH, Roth MS. (1994) Sensitive detection of occult breast cancer by the reverse-transcriptase polymerase chain reaction. J. Clin. Oncol. 12: 475-482.

15. Brown DC, Purushotham AD, Birnie GD,
George WD. (1995) Detection of intraoperative tumor cell dissemination in patients with breast cancer by use of reverse transcription and polymerase chain reaction. Surgery 117: 96-101.

16. Mayhew E, Glaves D. (1984) Quantitation of tumorigenic disseminating and arrested cancer cells. Br. J. Cancer 50: 159-166.

17. Weiss L. (1986) Metastatic inefficiency: Causes and consequences. Cancer Rev. 3: $1-24$.

18. Fidler IJ. (1970) Metastasis: Quantitative analysis of distribution and fate of tumor emboli labeled with ${ }^{125} \mathrm{I}$-5-iodo-2'-deoxyuridine. J. Natl. Cancer Inst. 45: 773-778.

19. Glaves D. (1983) Correlation between circulating cancer cells and incidence of metastases. Br. J. Cancer 48: 665-673.

20. Riethmuller G, Schneider-Gadicke E, Schlimok G, et al. (1994) Randomised trial of monoclonal antibody for adjuvant therapy of resected Dukes' C colorectal carcinoma. Lancet 343: 1177-1183. 